\title{
Investigation of the Impacts of the Leaning Community Program on Students' Learning
}

\author{
Su-Ching Lin \\ National Changhua University of Education, Taiwan \\ E-mail: sclin@cc.ncue.edu.tw \\ Ming-Sui Wu \\ Ming-Chuan University, Taiwan \\ E-mail:mswu@mail.mcu.edu.tw
}

Received: June 6, 2017 Accepted: June 26, 2017 Published: June 28, 2017

doi: 10.5296/jsss.v5i1.11364 URL: http://doi.org/10.5296/jsss.v5i1.11364

\begin{abstract}
The purpose of the study aimed to investigate the impacts of the SDPP (Students' Dialogue Praxis Program) on students' learning. SDPP was based on the perspectives and strategies of learning community (LC) advocated by Manabu Sato and LC related studies. The core concepts of SDPP included the dialogues with teaching materials, with the peers, and with oneself and majorly included three kinds of learning activities, learning by doing, collaborative learning, and reflective learning. The participants consisted of 106 eight graders from the same junior high school located in central Taiwan. Of 106 participants, 53 students who were the experimental group attending SDPP and 53 students who were the control group not taking any such intervention program. Results found that the experimental group acquired the scores from the communications survey, learning attitude survey, and critical thinking survey significantly higher than those of the control group. The study confirmed that SDPP made remarkable positive impacts on students' communicative capability, learning attitude, and critical thinking ability. Based on the findings, the suggestions for the teachers were also made in this study.
\end{abstract}

Keywords: Learning community, Program evaluation, Program theory-driven evaluation, Student dialogue praxis program 


\section{Introduction}

Manabu Sato, a Japanese scholar, advocated the perspective and strategies of learning community (LC), which created the reform of basic education in Japan and influences extended from Japan to other Asian countries. Sato urged LC perspective because of responding to his observation, in which he found that there was a lack of learning motivation getting popular with youngsters in schooling. The reason was that traditional schooling, encouraged competition rather than cooperation; encouraged testing knowledge content rather than connecting learning with lives, and only stressed academic achievement rather than honoring multiple bits of intelligence. Therefore, students isolated and less interaction with people; did not know the meaning and value of learning so that they escaped from learning (Sato, 2012a; Huang, 2013). In order to overcome the crisis of students escaping from learning, Sato suggested converting reluctant learning into an enjoyable learning because reluctant learning would not encounter with any new things, dialogues, and meanings. Instead, enjoyable learning would encounter with new things, dialogue with the world, with peers, and with selves. Therefore, genuine learning is through encountering dialogue with new things and others to construct the world, a companion, and self and to continually weave the meanings and relationships between the world, others, and selves (Sato, 2012b).

Since 2012, many Taiwanese educators have tried to incorporate LC perspective and strategies into their teaching. From the various teaching fields, many changes would be found, such as teachers prepared their lessons together and dialogue with other teachers inspiring their confidence in the teaching profession; changed students learning attitudes from passive to active, and brought schools with more cultural interaction than before. However, educators also found some problems, such as teachers must strengthen their skills about how to ask productive questions; students lacked abilities for collaborative dialogues (Chen, 2013; Lin, 2013;; Weng, Huang, \& Lai, 2013; Zhang, 2013; Taipei elementary school learning community team, 2013). In addition, empirical studies pointed out LC teaching could enhance students' learning motivation and interests, improve the ability of independent thinking (Chen \& Shi, 2014; Hsu, 2013), enhanced team collaboration, strengthen communication skills, improved concentration, and inspired enthusiasm (Syue, 2014), assisted the student to learn more in-depth understanding, and knowledge creation (Jheng, 2013), cultivated group and helped the low achievement of student learning (Syue, 2014, Jheng, 2013), created the closer the relationship between teachers and students, increased pleasant learning atmosphere (Wong, Huang, \& Lai, 2013). In other words, LC teaching contributed to new teaching paradigm transformation, not only nurtured students with the good learning attitude, collaboration and but also improved their ability to think independently.

The natural science which is one of very important learning areas in the junior high schools aims to cultivate students' interest and enthusiasm in science; teamwork and communication with peers; ability to independent thinking and problem-solving skills. From the process of teaching and learning of the Natural Science, teach students how to learn to observe, questioning, planning, examining, induction, judgment, criticism, creating skills, particularly through the inquiry process of experiments or field observations, students learned the 
importance of carefulness, patience, and rigor. Thus, the experimental learning, collaborative learning, and reflective learning for Nature Science are particularly important. However, for a long time, secondary schools in Taiwan was impacted by entrance examination and students are staying in school longer for much repetitive practice. Education in this level emphasized on examinations and results, rote learning and memory rather than the application. The experimental learning, collaborative learning, and reflective learning are therefore limited (Pan, 2013). Moreover, for most students, Nature Science is a difficult subject, more prone to feelings of fear and frustration, some students even appeared "runaway from learning" (give up learning) said by Sato's. It is an important issue for Nature Science teachers in junior high schools to think about how to innovate the teaching and learning so that theseJunior high school students could encounter and dialogue with teaching materials, peers, and selves. Further, they can experience the value and significance of learning, enjoy the pleasure of learning, enhance the effectiveness of learning and teaching.

The program is designed to achieve the desired goal activities, these activities are planned and organized activities, not arbitrary action, expected to have an impact on participants (Chen, 1990; Royse, Thyer, Padgett, \& Logam, 2006). Program evaluation is that an evaluator systematically collects and analyzes data about the program, as a basis for judging value or the advantages and disadvantages of the program. There are various program evaluation models and each of them has its own underlying theories, advantages, and limitations. A program theory-driven evaluation (PTDE) approach is one of the program evaluation models, which through a program theory construct the program evaluation framework to provide evaluation questions of causal mechanisms and assess the effectiveness of the program. Smith (1994) pointed out that the purpose of program theory-driven evaluation is thus: a) to answer causal questions about a program, b) to explain how it works, and c) to provide recommendations for improvement. Most PTDE has three basic characteristics: (a) the detailed input, the mediation process, the expected relationship between short-and long-term outcomes, and to explain the situations of program intervention; (b) all assumptions in measure theory construct; (c) analysis of data to determine hypothetical relationships actual extent (Shadish, Cook, \& Campbell, 2002).

The main advantages of the PTDE model are to explain underlying causal mechanism in the program and to construct new knowledge modules, as replication scheme or an important basis for improved. This is beyond the achievement of other types of evaluation models (Bickman, 1987; Davidson, 2000; Jacobs, Sisco, Hill, Malter, \& Figueredo, 2012) so PTDE was increasing important among evaluation community. Simply stated, theory-driven program evaluation is a comprehensive approach which involves three general steps (Donaldson, 2003, 2007): developing program theory, formulating and prioritizing evaluation questions, and answering evaluation questions. Six basic types of theory-driven evaluation (Chen, 1990) included normative treatment evaluation, normative implementation environment evaluation, normative outcome evaluation, impact evaluation, intervening mechanism evaluation, and generalization evaluation.

Based on the above, the current study was based on the perspectives and strategies of learning community (LC) advocated by Manabu Sato and LC related studies and Natural Science 
books of seventh grade to design the SDPP (Students' Dialogue Praxis Program). The core concepts of SDPP included the dialogues with teaching materials, with the peers, and with oneself and majorly included three kinds of learning activities, experiential learning, collaborative learning, and reflective learning. Applying a PTDE approach to evaluate the impacts of the SDPP on students' learning focusing on the influences on students' communication skills, learning attitude, and critical thinking.

\section{Literature review}

\subsection{The Core Concepts and Curriculum Design of $L C$}

LC is an innovative thinking model of teaching and learning which emphasizes the nature of learning being the process of constantly woven in the relationships and meanings. Based on the concept of LC, Sato (2012a) redefined "learning" as through encountering with things and dialogue to establish the world, encountering and dialogue with others to build partners, and encountering and dialogue with yourself to construct the self. Thus, teachers must guide students commonly share and exchange of the dialogue, dialectical and series in the learning community, enhance the learning of quality (Sato, 2013a). In order to practice these three dialogues, concrete ways were through experiential learning (learning by doing) to encounter and dialogue with learning materials, through collaborative learning to encounter and dialogue with peers, and through reflective learning to convert knowledge and skills into statements or performance to present what they think and what they feel (You \& Lin, 2014). These three types of learning are described below:

First, experiential learning is to let the learners hands-on learning, persistent learning activities, from which to develop their knowledge and skills, a strong mind training, and a strong sense of achievement (Pergert, 2009; Smart \& Csapo, 2007). Sato (2012b) emphasizes students that have to meet and dialogue and things in order to construct the world which belongs to cognition (cultural) practices, students must be able to speak with a specific educational content through dialogue in order to produce learning and understanding of core concepts and skills in the field.

Second, collaborative learning is how to construct the basis of learning from each other, learning from each other are based on listening. A teacher's listening ability is not only hearing the content or opinion expressed by students but also through listening to affirm the existence of students, giving a sense of belonging. Teachers being able to hear student voices, triggering their own thinking, let themselves into the student' $s$ field of study, but also because of timely listening, line knowledge and the views of students, students think more deeply, to stimulate greater spark. Therefore, teachers standing on the same plane learning is an important part of collaborative learning (Sato, 2012b; Huang, 2012). Collaborative learning is the key to the challenging "extended learning" to stimulate and enrich students' thinking. Essentially, team members of collaborative learning are not competitive with each other, instead, they work together, each member stands at the same starting point and to solve problems (Sato, 2013a). In other words, collaborative learning focuses on cultural practices or social practice. The goal of collaborative learning is not to express his or her opinion, but rather to listen to each other carefully and to think deeply so that learning will occur. Sato 
proposed the three important elements to create learning and teachers should be based on these three elements to the design and carry out collaborative learning (Sato, 2013a): (a) authentic learning which refers to teachers in the classroom to "listen to dialogue", "in-line thinking", "go back to the textbook" (the origin of knowledge). The processes of authentic learning should conform to the nature of the course. If teaching and learning could not conform to the nature of the course will be unable to achieve the quality of learning. (b) Mutual learning which refers to pursuing listening to each other rather than expressing his/her opinion. (c) Core topics and extended learning which refers to collaborative learning must be based on "the core topics" (the basic concepts of the textbook) and "extended learning" (the level beyond textbook) as the basis to design the course content. The core topics are that every student must be understood, instead, extended learning is based on the understandings of core topics and challenge beyond the textbook level learning.

In addition, cooperative learning in technical aspects includes (a) grouping which Sato (2012a) recommended that collaborative learning team-best composed of four students in order to establish a mutual learning relationship. The basic assumption of LC is that every student can collaborative learning with anyone. A teacher pleases encourage members to support each other, learn from each other no matter whether or not he/ she is a higher academic achievement or lowers. (b) The introduction and end of group learning: Sato (2013a) suggested that a teacher starts to teach core topics and later guides students to learn extended topics. At the end of group learning or learning must reply before the end of the class discussion, help students concentrate on their studies. In group activities, teachers must not involve as much as possible not to participate in the discussion of student and stagnant group, grant minimal assistance. (c) The classroom configuration: $\Pi$-shaped seating arrangement is to engage every student in collaborative learning the basic topics when in the classroom mutual relationships mature, be sure to try teaching together in a group.

Third, reflections on learning is a sense of dialogue, from a focus on access to knowledge and skill convert works to speak or think for themselves. Introspection (reflection) is the knowledge of experience, problem, or both, active thinking, and organization or the reconstruction process. Kemmis (1985) that the process of reflection is an internal and external dialectic, reflection on the individual not only safer thinking and thinking about the experience, and more see their environment. When taking into account the internal and external interaction, has more thought and reflection guide individual actions. Schön (1987) explored that practices affect learners in reflective learning on the application, this application can promote critical thinking ability and experience to reflect on. Furthermore, reflective learning Learning can promote the expression of knowledge, learners not only learn the knowledge, more knowledge to make acts of expression, from knowledge representation in the process of reflection on experience, knowledge construction (Harvey \& Knight, 1996).

\subsection{The Concepts of PTDE}

A program is an organized collection of activities designed to reach certain objectives. Organized activities - programs - are not a random set of actions, but a series of planned actions designed to solve any problem (Royse, Thyer, \& Padgett, 2010). Program evaluation 
can be seen as a subset of those activities labeled research, which itself has been simply defined as "systematic procedures used in seeking facts or principles" (Barker, 2003). In short words, program evaluation is a practical endeavor, not an academic exercise, and is not primarily an attempt to build a theory or necessary to develop social science knowledge (Royse, Thyer, \& Padgett, 2010). PTDE is one of program evaluation models which aims to answer questions about the causes, explains how this program works and provides recommendations for program improvement, whose main characteristic is the application of the theory of design and evaluation of intervention effect and understanding the relationship between causal mechanisms (Smith, 1994).

PTDE approaches are through the program's theory to construct a program evaluation framework, to provide evaluation questions, and assess the effectiveness of the program. Such an approach of program evaluation focuses on understanding the expected impact of the program, with the description of a specific program, explain program under which conditions will have an impact, and predict the outcome of the program. Although the evaluation process, the definition of program theory is still controversial, it is clear that program theory provided program evaluation with a logic of measurement and data collection, as expected and explain the process and results of the program and their associated basis (Blagg, 2011; Chen, 2005).

Many scholars present different views about program theory and its elements, such as Chen (1990) points out that social science scholars typically define "theory" to explain and predict phenomena interrelated propositions, however, such a definition is mostly descriptive theories which analyze the event itself and focuses on describing or explaining the facts and relationships. However, a descriptive theory is not the only type of theory. Another relating to the program evaluation theory is known as the prescriptive theory or normative theory. Normative theories of the program should be or what should be done to better recommendations, belongs to the requisite level of theory, including action orientation, treatment design, implementation of the conceptualization selection of performance criteria for results and so on.

Rossi, Freeman, and Lipsey (2004) argue that complete program theory should contain the program impact theory and program process theory. Program impact theory makes up concepts of operations, assumptions, description of the expectations of the causal relationship between changes in the program. Program process theory contains service utilization plan with the organizational plan, describing how the program compared to the targeted group interact to achieve the desired results, and how to deploy their resources and organization of activities to maintain the program development. Weiss (1998) argues that program theory is the basis for action, is the people in the plan was based on the assumption that the construction program, can be summarized as two theories: program theory and implementation theory, both called the program's theory of change. Weiss considered program evaluation needs to clearly distinguish the differences between program theory and implementation theory. If the program itself was based on the theory is wrong, even based on programming theory to implement program still does not have the desired effect; if the program theory is correct, but if you implement wrong, could not achieve the desired objectives of the program. Therefore, both theories will influence whether the programs 
succeed or not. Rogers (2008) pointed out that PTDE has two core elements: the conceptual and empirical. Conceptual means PTDE should articulate program theory or model is similar to normative theory; empirical means PTDE attempted to explore the theory of how the expected results of the program, is similar in descriptive theory.

Donaldson $(2003,2007)$ noted that PTDE is a comprehensive approach which involves three general steps including (a) developing program theory referring to PTDE theory is used to guide the evaluation of program design and implementation, the essence of which is the effective operation of the rationality and feasibility of the program model, concerned about the expected impact of the program, and from input to output in the secretive process of how to convert a series of propositions. Consequently, program theory is both descriptive and prescriptive; but also normative and practical. Once the development of a program theory or theories of the competitive program is completed, one should use these theories as a recognized evaluation issue and select evaluation methods based on. But if necessary, the evaluators may reassess whether the parts of the program theory or theories of comprehensive change program and decide whether or not to adjust them. (b) formulating and prioritizing evaluation questions referring to evaluators and stakeholders list a series of evaluation issues, systematic evaluation issues described in detail. Then, attempt to prioritize these issues, evaluators know very well that during the process of evaluation, which is reasonable, relevant, valuable and can respond to. (c) answer the evaluation questions referring to evaluation based on collected data, explain the causal linkages between theoretical constructs, including the direction and strength of the relationship between differences, the extent of regulating relations among other constructs such as, to respond to the concerns of stakeholders.

Chen (1990) expresses six basic types of PTDE including normative treatment evaluation, normative implementation environment evaluation, normative outcome evaluation, impact evaluation, intervening mechanism evaluation, and generalization evaluation described below: (a) normative treatment evaluation concerns the issues about intervention in this field of conceptualization and design, measurement of effective intervention in the field situation, assessment of the consistency between design and actual implementation. The specific evaluation questions might include the intervention of nature, element, elements of the organization and measurement. (b) Normative implementation environment evaluation concerns the issues, including whether or not treatment focuses on the targeted groups, implements have the required capabilities and professional qualifications? Transfer mode and inter-organizational coordination are appropriate and adequate? In short, this category aims to review and assess the implementation of the actual environment is consistent with the planning. (c) normative outcome evaluation concerns the achievement of the objectives or expected results of the program, often used to guide stakeholders' follow-up activities and decide on the allocation of resources and is often used as criteria for judging effectiveness program. (d) impact evaluation concerns causal inference, it must have sufficient and clear evidence, as a result assessment of program intervention intended or not intended results impact. (e) intervening mechanism evaluation concerns cause and effect link between intervention and outcome of the implementation process, that is, through the process of intervention and to explore ways to produce the desired results. (f) generalization evaluation 
concerns thinking about how to put the results of the assessment, extended to stakeholders are concerned about the future or for a specific person, environmental or institutional context.

\section{Methodology}

\subsection{Research Design and Participants}

The study applied a quasi-experimental design (shown in Table 1) to evaluate the impacts of SDPP on student's communication ability, learning attitudes, and critical thinking. The core concepts of SDPP included the dialogue with teaching materials, the dialogue with the peers, and the dialogue with oneself. SDPP majorly include three kinds of learning activities, learning by doing, collaborative learning, and reflective learning. Learning by doing refers to activities of exploration, explanation, induction, assumption, verification, and knowledge construction. Collaborative Learning refers to grouping students. Each group learns to listen to each other, to discuss with peers, and to construct knowledge during peer' sharing their opinions aside from cooperating with peers during doing individual assignments and extensive learning. Reflective Learning refers to activities of questioning the teaching materials, reflecting on the processes of learning experiences, and clarifying confusing concepts. SDPP Activities included lesson previews, experimental operation, discussion among the peers, filling out the worksheets, providing reflection and feedback, and activity records.

The sample consisted of 106 students from central Taiwan attending the same junior high school. They were divided into an experimental group and a control group and followed for a year-long study. The experimental group, comprising 53 students (26 girls and 27 boys), received SDPP instruction that lasted 45 minutes for a total of $180 \mathrm{~min}$ per week. The control group, consisting of 53 students ( 26 girls and 27 boys) who did not take any such intervention program. Two groups were taught by the same science teacher and with similar background and life experience of schooling before.

Table 1. The quasi-experimental design of SDPP

\begin{tabular}{llll}
\hline Group & Pre-test & Treatment & Posttest \\
\hline Experimental group & Y1 & $\mathrm{X}$ & Y3 \\
Control group & Y2 & & Y4 \\
\hline
\end{tabular}

Y1, Y2: Both experimental group and the control group are administered by the Pre-test of the Interpersonal Communication Scale (ICS), Learning Attitude Scale (LAS), and Critical Thinking Scale (CTS) before treatment.

X: represented experimental group accepted SDPP treatment, while the control group accepted the traditional instruction and did not take any such intervention program.

Y3, Y4: Both experimental group and control group were administered by the posttest of the ICS, LAS, and CTS after treatment. 


\subsection{Instruments}

During the research period, the data were collected through research instruments, ICS, LAS, and CTS which were developed in this study. ICS with ten items was designed to measure two sub-factors, including expression (5 items) and listening (5 items). Students were asked to rate the items on a five-point Likert scale anchoring at 1, 2, 3, 4, and 5 (from strongly disagree to strongly agree). The factor analysis made on data obtained by ICS in the current application reveals that each item in all subscale produced factor loadings was $52.14 \%$. The overall internal consistency (Cronbach's $\alpha=.83$ ) for the scale in the current sample was good. The Cronbach's $\alpha$ for the two subscales ranged .73 and .76, indicating good internal consistencies of the items within each subscale.

The second research instrument, LAS with twenty-two items was designed to measure five attitudes toward one's self (3 items), curriculum design (6 items), instructor (5 items), classmates (3 items), and learning resources ( 5 items). Students were asked to rate the items on a five-point Likert scale anchoring at 1,2,3,4, and 5 (from strongly disagree to strongly agree). The factor analysis made on data obtained by LAS in the current application reveals that each item in all subscale dimensions produced factor loadings was $62.26 \%$. The overall internal consistency (Cronbach's $\alpha=.89$ ) for the scale in the current sample was good. The Cronbach's $\alpha$ for the five subscales ranged from .65 to .85, indicating good internal consistencies of the items within each subscale.

The third research instrument, CTS with Twenty items was designed to measure four dimensions, including logicality and analysis, respect and open-mindedness, curiosity and innovation, trial and inquiry. Students were asked to rate the items on a five-point Likert scale anchoring at 1, 2, 3, 4, and 5 (from strongly disagree to strongly agree). The factor analysis made on data obtained by LAS in the current application reveals that each item in all subscale dimensions produced factor loadings was 63.90\%. The overall internal consistency (Cronbach's $\alpha=.93$ ) for the scale in the current sample was good. The Cronbach's $\alpha$ for the four subscales ranged from .75to .87 , indicating good internal consistencies of the items within each subscale.

\subsection{Data Analysis}

Data analysis was done using SPSS 20.0 for Windows. Results were analyzed using descriptive statistics in terms of distribution frequencies, percentages, mean values, and standard deviations. Inferential statistics were conducted using analysis of one-way covariance (one-way ANCOVA).

\section{Results}

\subsection{The Impact of SDPPon Students ' Communication Ability}

The current study used the teaching method as an independent variable and used the post-test of overall and subscales of ICS as dependent variables. The steps in ANCOVA were demonstrated as followings. 


\section{Macrothink}

\subsubsection{Testing of Homogeneity of Variance (HOV)}

Table 2 showed analysis results of testing of homogeneity of variance, which indicated after Levene's test, at the overall level $(\mathrm{F}=4.792, \mathrm{p}=.031)$ and expression level $(\mathrm{F}=8.285, \mathrm{p}$ $=.005)$, since $\mathrm{p}$-value less than $.05=\alpha$, we could reject the null hypothesis, and concluded there was a significant difference between these two groups, which did not satisfy the homogeneity of variances assumption, whereas at the listening level( $F=1.088, p=.300)$, since p-value greater than $.05=\alpha$, we could not reject the null hypothesis, and concluded there was no significant difference between these two groups, which satisfied the homogeneity of variances assumption.

Table 2. Teaching methods in the ICS pre-test analysis of Levene's test

\begin{tabular}{lllll}
\hline level & $F$ & $d f 1$ & $d f 2$ & $p$ \\
\hline expression & 8.285 & 1 & 90 & $.005^{* *}$ \\
listening & 1.088 & 1 & 90 & .300 \\
overall & 4.792 & 1 & 90 & $.031^{*}$ \\
\hline
\end{tabular}

${ }^{*} p<.05 .{ }^{* *} p<.01$.

\subsubsection{Testing of Regression Coefficient Homogeneity}

Table 3 showed that the teaching method of regression coefficient homogeneous test results within the Group (teaching methods ×pre-test scores of overall scale and subscales of ICS), the p-value was greater than.05, significantly, the slope of the regression of the same, which indicates ICS and subscale measured before and after the relationship would not be different due to different teaching methods, regression coefficient homogeneous assumed within the subject group, so ANCOVA analysis would be appropriate. 
Table 3. Teaching methods in ICS post-test analysis of regression coefficient homogeneous test

\begin{tabular}{lllllll}
\hline level & Sources of variation & $S S$ & $d f$ & $M S$ & $F$ & $p$ \\
\hline expressio & treatment * pre-test & .057 & 1 & .057 & .484 & .489 \\
$\mathrm{n}$ & error & 10.353 & 88 & .118 & & \\
\multirow{2}{*}{ listening } & sum & 1439.583 & 92 & & & \\
& treatment * pre-test & .136 & 1 & .136 & 1.671 & .200 \\
& error & 7.140 & 88 & .081 & & \\
sum & sum & 1493.000 & 92 & & & \\
& treatment * pre-test & .066 & 1 & .066 & .924 & .339 \\
& error & 6.239 & 88 & .071 & & \\
& sum & 1460.320 & 92 & & & \\
\hline
\end{tabular}

\subsubsection{Analyses of One-way ANCOVA}

The analyses of results of one-way ANCOVA as shown in Table 4 and Table 5, showed a significant overall main group effects of the overall level $(\mathrm{F}=16.757, \eta 2=.407, \mathrm{p}<.001)$, expression level $(\mathrm{F}=16.073, \eta 2=.287, \mathrm{p}<.001)$, and listening level $(\mathrm{F}=7.794, \eta 2=.413$, $\mathrm{p}<.01$ ), which indicated significant differences between the experimental and control groups on scores of the overall scale and subscales of ICS. Results showed that the experimental group performed significantly better than the control group in interpersonal communication ability. That is, while the pretest scores controlled, the experimental group outperformed the control group in post-test scores of overall and subscales in ICS.

Table 4 .Teaching methods in adjusted means of the ICS post-test

\begin{tabular}{lllclll}
\hline \multirow{2}{*}{ treatment } & $M$ & $S D$ & \multicolumn{3}{l}{$95 \% \mathrm{CI}$} \\
\cline { 5 - 6 } expression & experimental & 4.060 & .047 & 3.966 & 4.154 \\
& control & 3.766 & .055 & 3.657 & 3.876 \\
listening & experimental & 4.082 & .039 & 4.004 & 4.160 \\
& control & 3.914 & .046 & 3.823 & 4.005 \\
Overall & experimental & 4.067 & .037 & 3.995 & 4.140 \\
& control & 3.837 & .043 & 3.752 & 3.921 \\
\hline
\end{tabular}

Note. $\mathrm{CI}=$ confidence interval; $\mathrm{LL}=$ lower level; $\mathrm{UL}=$ upper level. 


\section{Macrothink}

Table 5. Teaching methods in the ICS post-test analysis of one-way ANCOVA

\begin{tabular}{|c|c|c|c|c|c|c|c|}
\hline level & $\begin{array}{l}\text { Sources } \\
\text { variation }\end{array}$ & of & $d f$ & $M S$ & $F$ & $\eta^{2}$ & $p$ \\
\hline \multirow[t]{3}{*}{ expression } & $\begin{array}{l}\text { treatment } \\
\text { post-test }\end{array}$ & $* 1.880$ & 1 & 1.880 & 16.073 & .287 & $.000^{* * *}$ \\
\hline & error & 10.409 & 89 & .117 & & & \\
\hline & sum & 1439.583 & 92 & & & & \\
\hline \multirow[t]{3}{*}{ listening } & $\begin{array}{l}\text { treatment } \\
\text { post-test }\end{array}$ & *.637 & 1 & .637 & 7.794 & .413 & $.006^{* *}$ \\
\hline & error & 7.276 & 89 & .082 & & & \\
\hline & sum & 1493.000 & 92 & & & & \\
\hline \multirow[t]{3}{*}{ overall } & $\begin{array}{l}\text { treatment } \\
\text { post-test }\end{array}$ & ${ }^{*} 1.187$ & 1 & 1.187 & 16.757 & .407 & $.000^{* * *}$ \\
\hline & error & 6.305 & 89 & .071 & & & \\
\hline & sum & 1460.320 & 92 & & & & \\
\hline
\end{tabular}

Based on the above analyses, this study confirmed that the SDPP provided remarkable positive influences on student's communication ability in the case study.

\subsection{The Impact of SDPPon Students'Learning Attitudes}

The current study used the teaching method as an independent variable and used the post-test of overall and subscales of LAS as dependent variables. The steps in ANCOVA were demonstrated as followings.

\subsubsection{Testing of Homogeneity of Variance}

Table 6 showed analysis results of testing of homogeneity of variance, which indicated after Levene's test, only at the curriculum design level $(\mathrm{F}=4.417, \mathrm{p}=.038)$, since $\mathrm{p}$-value less than $.05=\alpha$, we could reject the null hypothesis, and concluded there was a significant difference between these two groups, which did not satisfy the homogeneity of variances assumption, whereas at the levels of oneself $(\mathrm{F}=.453, \mathrm{p}=.502)$, instructor $(\mathrm{F}=1.407, \mathrm{p}$ $=.239)$, classmates $(\mathrm{F}=.673, \mathrm{p}=.414)$, learning resources $(\mathrm{F}=1.221, \mathrm{p}=.272)$, and overall $(\mathrm{F}=.001, \mathrm{p}=.974)$, since $\mathrm{p}$-value greater than $.05=\alpha$, we could not reject the null hypothesis, and concluded there was no significant difference between these two groups, which satisfied the homogeneity of variances assumption. 
Table 6. Teaching methods in the LAS pre-test analysis of Levene's test

\begin{tabular}{lllll}
\hline level & $F$ & $d f 1$ & $d f 2$ & $p$ \\
\hline one's self & .453 & 1 & 90 & .502 \\
curriculum design & 4.417 & 1 & 90 & $.038^{*}$ \\
instructor & 1.407 & 1 & 90 & .239 \\
classmates & .673 & 1 & 90 & .414 \\
learning resources & 1.221 & 1 & 90 & .272 \\
overall & .001 & 1 & 90 & .974 \\
\hline
\end{tabular}

* $p<.05$

\subsubsection{The Test of regression Homogeneity}

Table 7 showed that the teaching method of regression coefficient homogeneous test results within the Group (teaching methods $\times$ pre-test scores of overall scale and subscales of LAS), the p-value was greater than.05, significantly, the slope of the regression of the same, which indicates LAS and subscale measured before and after the relationship would not be different due to different teaching methods, regression coefficient homogeneous assumed within the subject group, so ANCOVA analysis would be appropriate.

Table 7. Teaching methods in LAS post-test analysis of regression coefficient homogeneous test

\begin{tabular}{lllllll}
\hline level & Source of variation & $S S$ & $d f$ & $M S$ & $F$ & $p$ \\
\hline one's self & treatment * pre-test & .140 & 1 & .140 & .898 & .346 \\
& error & 13.679 & 88 & .155 & & \\
& sum & 1433.556 & 92 & & & \\
curriculum design & treatment * pre-test & .033 & 1 & .033 & .377 & .541 \\
& error & 7.669 & 88 & .087 & & \\
instructor & sum & 1420.444 & 92 & & & \\
& treatment * pre-test & .009 & 1 & .009 & .087 & .768 \\
& error & 9.304 & 88 & .106 & & \\
classmates & sum & 1408.640 & 92 & & & \\
& treatment * pre-test & .042 & 1 & .042 & .277 & .600 \\
& error & 13.315 & 88 & .151 & & \\
& sum & 1490.778 & 92 & & &
\end{tabular}




$\begin{array}{lllllll}\text { learning resources } & \text { treatment * pre-test } & .175 & 1 & .175 & 2.221 & .140 \\ & \text { error } & 6.924 & 88 & .079 & & \\ \text { sum } & 1458.762 & 92 & & & \\ \text { overall } & \text { treatment * pre-test } & .059 & 1 & .059 & 1.768 & .187 \\ & \text { error } & 2.913 & 88 & .033 & & \\ & \text { sum } & 1427.746 & 92 & & \end{array}$

\subsubsection{Analysis of One-way Covariance (One-way ANCOVA)}

The analyses of results of one-way ANCOVA as shown in Table 8 and Table 9, showed a significant overall main group effects of the overall level $(F=75.147, \eta 2=.748, p<.001)$, and levels of curriculum design $(\mathrm{F}=27.990, \eta 2=.652, \mathrm{p}<.001)$, instructor $(\mathrm{F}=20.243, \eta 2=.502$, $\mathrm{p}<.001)$, classmates $(\mathrm{F}=13.698, \eta 2=.503, \mathrm{p}<.001)$, and learning resources $(\mathrm{F}=49.528$, $\eta 2=.491, \mathrm{p}<.001)$, which indicated significant differences between the experimental and control groups on scores of the overall scale and subscales of LAS. Results showed that the experimental group performed significantly better than the control group in learning attitudes. That is, while the pretest scores controlled, the experimental group outperformed the control group in post-test scores of overall and subscales in LAS.

Table 8. Teaching methods in adjusted means of the LAS post-test

\begin{tabular}{|c|c|c|c|c|c|}
\hline \multirow[b]{2}{*}{ level } & \multirow[b]{2}{*}{ Treatment } & \multirow[b]{2}{*}{$M$} & \multirow[b]{2}{*}{$S D$} & \multicolumn{2}{|c|}{$95 \% \mathrm{CI}$} \\
\hline & & & & $L L$ & $U L$ \\
\hline \multirow[t]{2}{*}{ one's self } & experimental & 3.983 & .054 & 3.874 & 4.091 \\
\hline & control & 3.836 & .064 & 3.709 & 3.962 \\
\hline \multirow[t]{2}{*}{ curriculum design } & experimental & 4.040 & .041 & 3.959 & 4.121 \\
\hline & control & 3.706 & .048 & 3.611 & 3.800 \\
\hline \multirow[t]{2}{*}{ instructor } & experimental & 4.018 & .045 & 3.930 & 4.107 \\
\hline & control & 3.708 & .052 & 3.605 & 3.812 \\
\hline \multirow[t]{2}{*}{ classmates } & experimental & 4.119 & .053 & 4.012 & 4.225 \\
\hline & control & 3.813 & .062 & 3.689 & 3.937 \\
\hline \multirow[t]{2}{*}{ learning resources } & experimental & 4.141 & .039 & 4.064 & 4.218 \\
\hline & control & 3.722 & .045 & 3.632 & 3.812 \\
\hline \multirow[t]{2}{*}{ overall } & experimental & 4.067 & .025 & 4.016 & 4.117 \\
\hline & control & 3.729 & .029 & 3.670 & 3.787 \\
\hline
\end{tabular}

Note. $\mathrm{CI}=$ confidence interval; $\mathrm{LL}=$ lower level; $\mathrm{UL}=$ upper level. 
Table 9. Teaching methods in the LAS post-test analysis of one-way ANCOVA

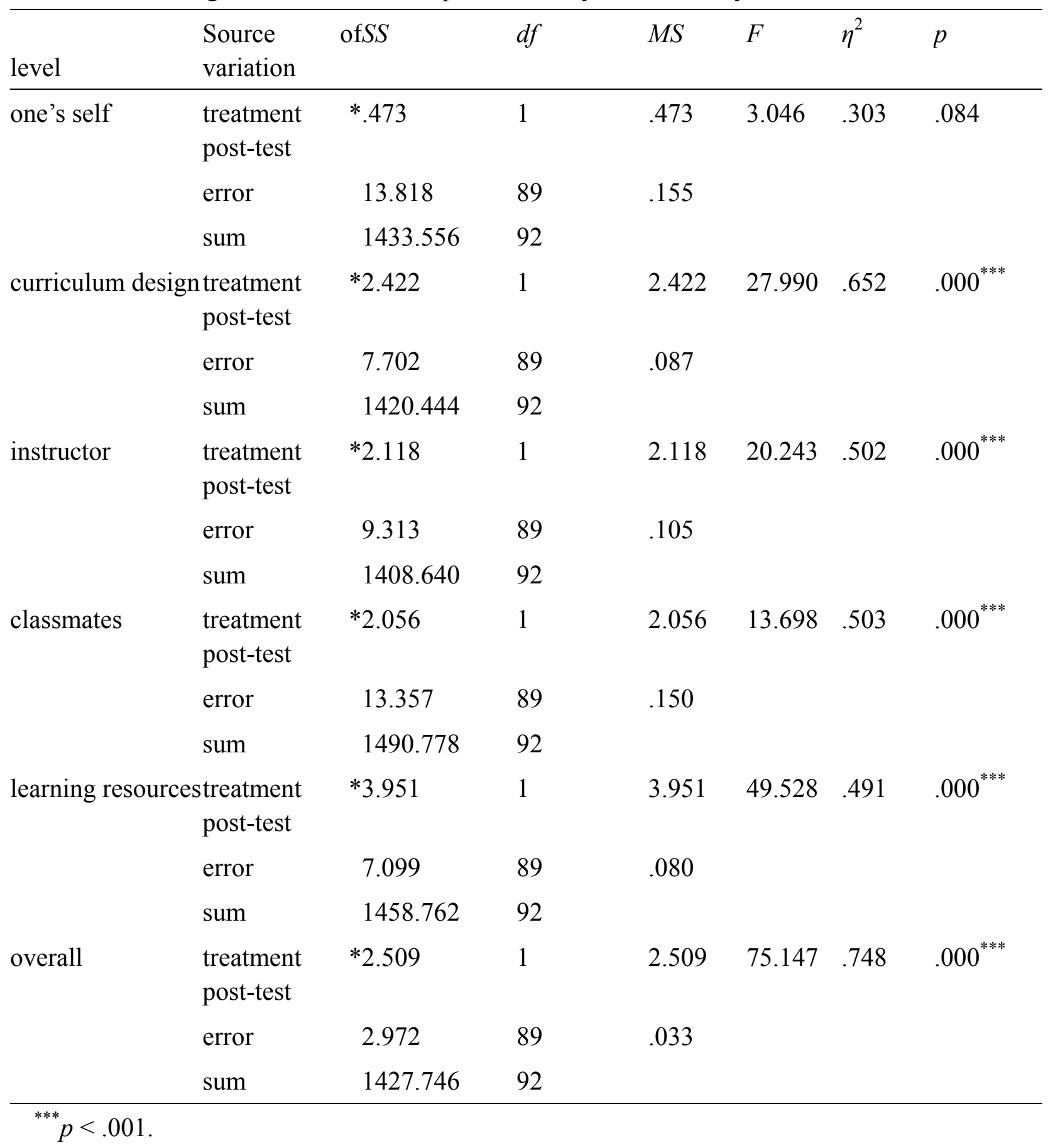

Based on the above analyses, this study confirmed that the SDPP provided remarkable positive influences on students'learning attitudes in the case study.

\subsection{The Impact of SDPPon Students' Critical Thinking}

The current study used the teaching method as an independent variable and used the post-test of overall and subscales of CTS as dependent variables. The steps in ANCOVA were demonstrated as followings. 


\section{Macrothink}

Journal of Social Science Studies

ISSN 2329-9150

2018, Vol. 5, No. 1

\subsubsection{Testing of Homogeneity of Variance}

Table 10 showed analysis results of testing of homogeneity of variance, which indicated after Levene's test, all levels of CTS, since p-value greater than $.05=\alpha$, we could not reject the null hypothesis, and concluded there was no significant difference between these two groups, which satisfied the homogeneity of variances assumption.

Table 10. Teaching methods in the CTS pre-test analysis of Levene's test

\begin{tabular}{lllll}
\hline level & $F$ & $d f 1$ & $d f 2$ & $p$ \\
\hline logicality and analysis & 1.340 & 1 & 90 & .250 \\
respect and open-mindedness & 1.862 & 1 & 90 & .176 \\
curiosity and innovation & .525 & 1 & 90 & .470 \\
trial and inquiry & .069 & 1 & 90 & .793 \\
overall & 3.908 & 1 & 90 & .051 \\
\hline
\end{tabular}

\subsubsection{The Test of Regression Homogeneity}

Table 11 showed that the teaching method of regression coefficient homogeneous test results within the Group (teaching methods xpre-test scores of overall scale and subscales of CTS), the p-value was greater than.05, significantly, the slope of the regression of the same, which indicates CTS and subscale measured before and after the relationship would not be different due to different teaching methods, regression coefficient homogeneous assumed within the subject group, so ANCOVA analysis would be appropriate.

Table 11.Teaching methods in CTS post-test analysis of regression coefficient homogeneous test

\begin{tabular}{|c|c|c|c|c|c|c|}
\hline level & Source of variation & $S S$ & $d f$ & $M S$ & $F$ & $p$ \\
\hline \multirow{3}{*}{$\begin{array}{l}\text { logicality and } \\
\text { analysis }\end{array}$} & treatment $*$ pre-test & .157 & 1 & .157 & 2.002 & .161 \\
\hline & error & 6.905 & 88 & .078 & & \\
\hline & sum & 1414.796 & 92 & & & \\
\hline \multirow{3}{*}{$\begin{array}{l}\text { respect and } \\
\text { open-mindedn } \\
\text { ess }\end{array}$} & treatment $*$ pre-test & .007 & 1 & .007 & .060 & .806 \\
\hline & error & 10.510 & 88 & .119 & & \\
\hline & sum & 1449.778 & 92 & & & \\
\hline \multirow{3}{*}{$\begin{array}{l}\text { curiosity and } \\
\text { innovation }\end{array}$} & treatment $*$ pre-test & .015 & 1 & .015 & .276 & .601 \\
\hline & error & 4.679 & 88 & .053 & & \\
\hline & sum & 1483.959 & 92 & & & \\
\hline
\end{tabular}




\begin{tabular}{|c|c|c|c|c|c|c|}
\hline \multirow{3}{*}{$\begin{array}{l}\text { trial } \\
\text { inquiry }\end{array}$} & treatment $*$ pre-test & .031 & 1 & .031 & \multirow[t]{2}{*}{.204} & \multirow[t]{2}{*}{.652} \\
\hline & error & 13.466 & 88 & .153 & & \\
\hline & sum & 1412.556 & 92 & & & \\
\hline \multirow{3}{*}{ overall } & treatment $*$ pre-test & .000 & 1 & .000 & .010 & .920 \\
\hline & error & 2.591 & 88 & .029 & & \\
\hline & sum & 1437.905 & 92 & & & \\
\hline
\end{tabular}

\subsubsection{Analysis of One-Way Covariance (one-way ANCOVA)}

The analyses of results of one-way ANCOVA as shown in Table 12 and Table 13, showed a significant overall main group effects of the overall level $(F=162.084, \eta 2=.768, p<.001)$, and levels of logicality and analysis $(\mathrm{F}=89.525, \eta 2=.624, \mathrm{p}<.001)$, respect and open-mindedness $(\mathrm{F}=48.311, \eta 2=.478, \mathrm{p}<.001)$, curiosity and innovation $(\mathrm{F}=37.340$, $\eta 2=.516, \mathrm{p}<.001)$, and trial and inquiry $(\mathrm{F}=44.842, \eta 2=.506, \mathrm{p}<.001)$, which indicated significant differences between the experimental and control groups on scores of the overall scale and subscales of CTS. Results showed that the experimental group performed significantly better than the control group in critical thinking ability. That is, while the pretest scores controlled, the experimental group outperformed the control group in post-test scores of overall and subscales in CTS.

Table 12. Teaching methods in adjusted means of the CTS post-test

\begin{tabular}{|c|c|c|c|c|c|}
\hline \multirow[b]{2}{*}{ Dimension } & \multirow[b]{2}{*}{ treatment } & \multirow[b]{2}{*}{$M$} & \multirow[b]{2}{*}{$S D$} & \multicolumn{2}{|c|}{$95 \% \mathrm{CI}$} \\
\hline & & & & $L L$ & $U L$ \\
\hline \multirow[t]{2}{*}{ logicality and analysis } & is experimental & 4.134 & .039 & 4.057 & 4.211 \\
\hline & control & 3.572 & .045 & 3.482 & 3.662 \\
\hline \multirow{2}{*}{$\begin{array}{l}\text { respect } \\
\text { open-mindedness }\end{array}$} & indexperimental & 4.156 & .047 & 4.063 & 4.250 \\
\hline & control & 3.651 & .055 & 3.541 & 3.760 \\
\hline \multirow{2}{*}{$\begin{array}{l}\text { curiosity } \\
\text { innovation }\end{array}$} & ndexperimental & 4.129 & .032 & 4.066 & 4.191 \\
\hline & control & 3.833 & .037 & 3.759 & 3.906 \\
\hline \multirow[t]{2}{*}{ trial and inquiry } & experimental & 4.116 & .054 & 4.009 & 4.223 \\
\hline & control & 3.560 & .063 & 3.436 & 3.685 \\
\hline \multirow[t]{2}{*}{ overall } & experimental & 4.132 & .023 & 4.086 & 4.179 \\
\hline & control & 3.674 & .027 & 3.620 & 3.728 \\
\hline
\end{tabular}

Note. $\mathrm{CI}=$ confidence interval; $\mathrm{LL}=$ lower level; $\mathrm{UL}=$ upper level. 
Table 13. Teaching methods in the CTS post-test analysis of one-way ANCOVA

\begin{tabular}{|c|c|c|c|c|c|c|c|}
\hline Dimension & Source of variation & $S S$ & $d f$ & $M S$ & $F$ & $\eta^{2}$ & $p$ \\
\hline \multirow{3}{*}{$\begin{array}{l}\text { logicality } \\
\text { analysis }\end{array}$} & \multicolumn{2}{|c|}{ andtreatment $*$ post-test 7.104} & 1 & 7.104 & \multirow[t]{3}{*}{89.525} & \multirow[t]{3}{*}{.624} & \multirow[t]{3}{*}{$.000^{* * *}$} \\
\hline & error & 7.062 & 89 & .079 & & & \\
\hline & sum & 1414.796 & 92 & & & & \\
\hline respect al & \multicolumn{2}{|c|}{ andtreatment $*$ post-test 5.709} & 1 & 5.709 & 48.311 & .478 & $.000^{* * *}$ \\
\hline \multirow[t]{2}{*}{ open-mindedness } & ss error & 10.517 & 89 & .118 & & & \\
\hline & sum & 1449.778 & 92 & & & & \\
\hline \multirow{3}{*}{$\begin{array}{l}\text { curiosity } \\
\text { innovation }\end{array}$} & \multicolumn{2}{|c|}{ andtreatment $*$ post-test 1.969} & 1 & 1.969 & \multirow[t]{3}{*}{37.340} & \multirow[t]{3}{*}{.516} & \multirow[t]{3}{*}{$.000^{* * *}$} \\
\hline & error & 4.693 & 89 & .053 & & & \\
\hline & sum & 1483.959 & 92 & & & & \\
\hline \multirow[t]{3}{*}{ trial and inquiry } & \multicolumn{2}{|c|}{ treatment $*$ post-test 6.801} & 1 & 6.801 & \multirow[t]{3}{*}{44.842} & \multirow[t]{3}{*}{.506} & \multirow[t]{3}{*}{$.000^{* * *}$} \\
\hline & error & 13.497 & 89 & .152 & & & \\
\hline & sum & 1412.556 & 92 & & & & \\
\hline \multirow[t]{3}{*}{ overall } & \multicolumn{2}{|c|}{ treatment $*$ post-test 4.718} & 1 & 4.718 & \multirow[t]{3}{*}{162.084} & \multirow[t]{3}{*}{.768} & \multirow[t]{3}{*}{$.000^{* * *}$} \\
\hline & error & 2.591 & 89 & .029 & & & \\
\hline & sum & 1437.905 & 92 & & & & \\
\hline
\end{tabular}

Based on the above analyses, this study confirmed that the SDPP provided remarkable positive influences on student's critical thinking in the case study.

\section{Conclusion and Suggestion}

This study aimed to apply Learning Community (LC) philosophy advocated by Japanese Scholar Manabu Sato and his previous studies to design and implement SDPP. The SDPP was involved in three leanings, including experiential learning, collaborative learning, and reflective learning. The program evaluation focused on investigating the impacts of the SDPP on students' communication ability, learning attitude, and critical thinking ability. The study applied a quasi-experimental research design. The participants included 106 eight-graders from the same school. Three instruments, ICS, LAS, and CTS were developed to collect pre-test and post-test data. Results found that the experimental group acquired the scores from the communication scale, learning attitude scale, and critical thinking scale significantly higher than those of the control group. The study confirmed that SDPP made remarkable positive impacts on students' communication ability, learning attitude, and critical thinking ability. Based on the findings, three suggestions were made for the science teachers in this study.

First, to cultivate the students' ability to express and listen through collaborative learning. It 
was found that SDPP provided a significantly positive influence on social communication capability to those experimental group students in this study. Therefore, this study suggested that the teachers cultivate students' expression and listening ability by applying the methods of collaborative learning in their teaching activities. As Manabu Sato stated, the foundation of "collaborative learning" was how to construct the relationship of mutual learning, which was based on "mutual listening". What collaborative learning pursued was the varieties of students' thinking and more understanding rather than the consistency of thinking and opinions within the group. So collaborative learning could bring up the students' ability to express and listen.

Second, to improve students' learning attitude by taking advantage of experiential learning. It was discovered that those experimental group students got the positive impact from SDPP on all aspects such as the attitude to themselves, to the instructors, to classmates, and to learning resources. Accordingly, this study suggested that teachers take advantage of experiential learning methods to bring up students' positive learning attitude. As Manabu emphasized, in cognitive practice, students must be able to have dialogues with specific educational contents, produce learning through dialogues, and then understand the core concepts and skills of the learning area. Let the students do the works themselves through experiential learning. So that the learning activities could last longer, and students could develop knowledge and ability, strengthen thinking training, get a sense of accomplishment from it, raise learning motivation and cultivate a positive learning attitude.

Third, to enhance students' critical thinking ability by implementing reflective learning. In this study, it was found that those experimental group students had higher scores on rational and objective, respect and objective, curious and innovative, attempt and explore and significant improvement in overall levels. SDPP showed positive impacts on students' critical thinking ability. Thence, this study suggested teachers implement reflective learning in the teaching activities. So that students could review the self-learning process from the beginning to the end of learning, and then solve the problems or reconstruct knowledge. It could achieve the goal of improving learning quality and thus promote learning performance through the feedbacks and reviews of reflective thinking. The strategy of reflective learning could inspire students' reflective ability through the dialogue between the teacher and students. It also could improve students' critical thinking ability through learning archives or learning journals by writing to record learning materials or activity responses and to self-evaluate on what important concepts they had learned in the classes.

\section{Acknowledgement}

The research is financed by Ministry of Science and Technology, Taiwan under Contract No. MOST 105-2410-H-018 -017 -MY2

\section{References}

Bickman, L. (1987). The functions of program theory. New Directions for Program Evaluation, 33, 5-18. https://doi.org/10.1002/ev.1443

Blagg, R. D. (2011). A bridge between basic social science and evaluation. In S. Mathison 
(Ed.), Really new directions in evaluation: Young evaluators'perspectives. New Directions for Evaluation, 131, 27-30. https://doi.org/10.1002/ev.374

Chang, Y.-C. (2013). A senior high school teacher's reflection of the learning community. Taiwan Education Review Monthly, 2 (3), 63-64.

Chen, H. T. (1990). Theory-driven evaluations. Newbury-Park, CA: Sage. https://doi.org/10.4135/9781412985444

Chen, H. T. (2005). Practical program evaluation: Assessing and improving planning, implementation, and effectiveness. Thousand Oaks, CA: Sage. https://doi.org/10.1002/ev.1178

Chen, S.-Z. (2013). Ignite the learning passion through the game - my little teaching revolution. Taipei, Taiwan: Common Wealth.

Davidson, E. J. (2000). Ascertaining causality in theory-based evaluation. In P. J. Rogers, T. A. Hasci, A. Petrosino, \& T. A. Huebner (Eds.), Program theory in evaluation: Challenges and opportunities (pp. 17-26). San Francisco, CA: Jossey-Bass.

Donaldson, S. I. (2003). Theory-driven program evaluation in the new millennium. In S. I. Donaldson \& M. Scriven (Eds.), Evaluating social programs and problems: Visions for the new millennium (pp. 109-141). Mahwah, NJ: Lawrence Erlbaum.

Donaldson, S. I. (2007). Program theory-driven evaluation science. New York: Lawrence Erlbaum.

Harvey, L., \& Knight, P. (1996). Transforming higher education. Buckingham, England: Society for Research in Higher Education and Open University Press.

Jacobs, W. J., Sisco, M., Hill, D., Malter, F., \& Figueredo, A. J. (2012). Evaluating theory-based evaluation: Information, norms, and adherence. Evaluation and Program Planning, 35, 354-369. https://doi.org/10.1016/j.evalprogplan.2011.12.002

Kemmis, S. (1985). Action research and the politics of reflection. In D. Boud, R. Keogh, \& D. Walker (Eds.), Reflection: Turning experience into learning (pp. 139-163). London, England: Kogan Page.

Lin, Y.-P. (2013). Super exciting interactive, nobody sleeping in class. In Common Wealth (Ed.), Learning community -First time experience (pp. 99-104). Taipei, Taiwan: Common Wealth.

Manabu Sato., Ho, C.-Y., Bin, J.-S., \& Chen, Y.-H. (2013). Flipped education (Y.-L. Huang and G. -Q. Zhong Trans.). Taipei, Taiwan: Common Wealth.

Pergert, P. (2009). Methodological learning by-doing: Challenges, lessons learned and rewards. Grounded Theory Review, 8(2), 65-75.

Rogers, P. J. (2008). Using program theory to evaluate complicated and complex aspects of interventions. Evaluation, 14, 29-48. https://doi.org/10.1177/1356389007084674

Rossi, P.H., Lipsey, M. W., \& Freeman, H. E. (2004). Evaluation: A Systematic Approach (7th ed.). Beverly Hills, CA: Sage.

Royse, D., Thyer, B. A., Padgett, D. K., \& Logam, T. K. (2006). Program evaluation: An introduction (4th ed.). Belmont, CA: Thomson Brooks/Cole.

Royse, D., Thyer, B. A., \& Padgett, D. K. (2010). Program evaluation: An introduction (5th 


\section{Macrothink}

ed.). Belmont, CA: Wadsworth.

Sato, M. (2012a). Learning Revolution: starting from the classroom reform (Y.-L. Huang and G. -Q. Zhong Trans.). Taipei, Taiwan: Common Wealth. (Original work published 2000)

Sato, M. (2012b). Teacher's challenges: the quiet revolution in the classroom (G. -Q. Zhong Trans.). Shanghai, China: East China Normal University (Original work published 2012)

Sato, M. (2013a). Learning community: Conception and practice (Y.-L. Huang Trans.). Taipei, Taiwan: Common Wealth. (Original work published 2013)

Sato, M. (2013b). The forefront of the learning revolution: to retrieve the child's well-being in the learning community (Y.-L. Huang Trans.). Taipei, Taiwan: Common Wealth. (Original work published 2012)

Schmuck, R. A. (2006). Practical action research for change. Beverly Hills, CA: Sage.

Schön, D. (1987). Educating the reflective practitioner. San Francisco, CA: Jossey-Bass.

Shadish, W. R., Cook, T. D., \& Campbell, D. T. (2002). Experimental and quasi-experimental designs for generalized causal inference. Boston, MA: Houghton Mifflin.

Smart, K. L., \& Csapo, N. (2007). Learning by doing: Engaging students through learner-centered activities. Business Communication Quarterly, 70(4), 451-457. https://doi.org/10.1177/10805699070700040302

Smith, N. L. (1994). Clarifying and expanding the application of program theory-driven $\begin{array}{lllll}\text { evaluations. } & \text { Evaluation } & \text { Practice, } & 15 & \text { (1), }\end{array}$ https://doi.org/10.1016/0886-1633(94)90064-7

Taipei City Elementary School Learning Community Team (2013, March). Learning Community's record of five schools, paper presented at "Educational Leadership and Learning Community" international conference hosted by Graduate Institute of Educational Policy and Leadership of Tamkang University and the Taiwan Institute of Local Education Development. March 7-8, 2013. Taipei, Taiwan: Tamkang University

Weiss, C. H. (1998). Evaluation: Methods for studying programs and policies $\left(2^{\text {nd }}\right.$ ed.). Upper Saddle River, NJ: Prentice Hall.

\section{Copyright Disclaimer}

Copyright for this article is retained by the author(s), with first publication rights granted to the journal.

This is an open-access article distributed under the terms and conditions of the Creative Commons Attribution license (http://creativecommons.org/licenses/by/3.0/). 